\title{
Política e cultura no Brasil e na Costa Rica (1950 -1980)
}

Alexandre Barbalho

Resumo: O artigo analisa as políticas culturais no Brasil e na Costa Rica entre 195080 , tendo como referencial a experiência histórica das duas sociedades. Com base nesse contexto, discute como a presença do Estado na cultura responde, ou não, à tarefa de estabelecer uma identidade latino-americana plural.

Palavras-chave: Política;

Cultura; Latino-americanidade; Brasil; Costa Rica.

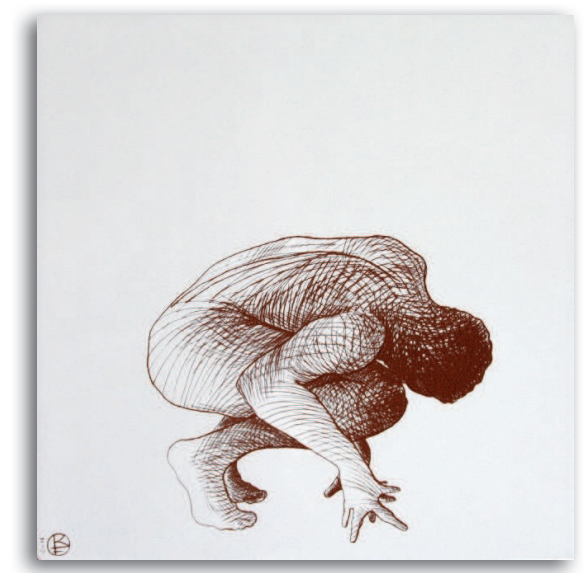

\section{Politics and culture in Brazil and Costa Rica (1950 -1980)}

Abstract: The article analyzes the cultural policies in Brazil and Costa Rica from 1950-80, taking as reference the historical experience of both societies. From this context, it discusses how the State's presence in the culture responds, or not, to the task of establishing a plural Latin American identity.

Keywords: Politcs; Culture; Latino

Alexandre Barbalho American Identity; Brazil; Costa Rica.

Professor do Mestrado

Acadêmico em

Políticas Públicas e

Sociedade da UECE e

do Departamento de

Comunicação da UFC. 


\section{INTRODUÇÃO}

Em ensaio no qual se pergunta o que significa ser latino-americano no início do século XXI, Nestor García Canclini coloca a seguinte hipótese: "Mesmo reconhecendo o vigor e a continuidade da história compartilhada, o latino-americano não é uma essência, e mais que uma identidade é uma tarefa" (CANCLINI, 2002, p. 32). ${ }^{1}$ Sua argumentação se desenvolve em torno de como três esferas profundamente inter-relacionadas da vida contemporânea podem informar sobre a latinoamericanidade: o Estado nacional, cujo sujeito é o cidadão; as indústrias culturais, cujo sujeito é o espectador; o mercado, cujo sujeito é o consumidor.

O interesse desse artigo é contribuir para a resposta sobre o que significa ser da América Latina com base na análise das políticas culturais implantadas no Brasil e na Costa Rica entre 195080. A partir desse contexto, proponho trabalhar como a presença do Estado na cultura e suas políticas respondem, ou não, à tarefa de estabelecer uma latinoamericanidade plural, aberta não apenas à diversidade, mas inclusive às diferenças. ${ }^{2}$ Uma América Latina onde o cidadão não se transforme apenas em consumidor (CANCLINI, 1997; BAUDRILLARD, 1995), e nem em mero espectador (DEBORD, 1997).

Não se trata de fazer uma análise comparativa entre Brasil e Costa Rica, no intuito de buscar dados estatísticos e parametrizáveis, mas aproximar a experiência histórica de duas culturas e das suas políticas, percebendo, sim, suas diferenças, como também, e diria principalmente, suas semelhanças. Afinal, trata-se, propositadamente, de duas realidades bem distintas, a brasileira e a costa-riquense. Portanto, a ideia de sobrepor essas duas experiências inspira-se na dialética da imagem benjaminiana que possibilita uma postura crítica a quem as observa.

1 No original: "[...] aun reconociendo el vigor y la continuidad de la historia compartida, lo latinoamericano no es una esencia, y más que una identidad es una tarea" (Tradução minha).

2 A distinção entre diversidade e diferença se faz necessária por conta da tradição de nossas políticas culturais de fazerem do discurso da diversidade um elemento de integração autoritária, esvaziando todo conflito advindo da diferença (BARBALHO, 2007). 
O recorte temporal justifica-se porque nele vigorou um dos mais fortes discursos generalistas sobre a realidade latino-americana, isto é, o do nacional-desenvolvimentismo, e que teve na Comissão Econômica para a América Latina (CEPAL), criada em 1948, seu principal centro de elaboração.

Nos anos 1980, a crise econômica colocou em xeque as políticas intervencionistas ditadas pelo pensamento desenvolvimentista e ganhou espaço a defesa do livre mercado e do receituário que ficou conhecido como neoliberal. Este fato reorientou as atuações dos governos latino-americanos, inclusive das suas políticas culturais, e resultou, em grande parte, no atual estado da condição latino-americana.

Como sustenta Canclini, o "assalto neoliberal" transformou radicalmente as relações entre o nacional e o global com suas políticas de abertura econômica, privatização, desregulamentação. Tais orientações, pelo menos em um primeiro momento, mostraram-se com uma extensa e eficaz capacidade operativa, de modo que "jamais uma política de reestruturação econômica, nem a populista, nem a desenvolvimentista, haviam conseguido impor-se de forma simultânea e com tal homogeneidade no conjunto dos países latino-americanos" (CANCLINI, 2002, p. 44). ${ }^{3}$

\section{POLÍTICA CULTURAL NO BRASIL (1950-1980): DA AUSÊNCIA À INTERVENÇÃO PLANEJADA}

A década de 1950 no Brasil foi um período de exercício da democracia, embora limitada, ${ }^{4}$ após quinze anos de regime varguista (1930-1945), marcado pelo autoritarismo, mas também por forte investimento na cultura. Naquele momento, o Estado brasileiro implementa a construção institucional no campo cultural, uma intervenção quase inaugural, porquanto desde a colonização até o ano de 1930, com exceção da presença da Corte portuguesa e

3 No original: "Jamás una política de reestructuración econômica, ni la populista ni la desarollista, habían logrado imponerse en forma simultânea y con tal homogeneidad en el conjunto de los países latinoamericanos" (Tradução minha).

4 O Partido Comunista Brasileiro, por exemplo, passa quase toda a década na clandestinidade. 
no reinado de D. Pedro II, poucas ações foram realizadas nesse sentido. ${ }^{5}$

Mas a redemocratização pós-Vargas, paradoxalmente, significou uma relativa letargia do governo federal na cultura, restringindo-se a manter, sem muito vigor, o que já vinha sendo feito desde o período imediatamente anterior. Isso em uma década que viveu, no plano político-institucional, um dos momentos mais ricos do projeto nacional-desenvolvimentista com o governo de Juscelino Kubitschek, e, no plano cultural, a efervescência da bossa-nova, da poesia concreta, da arquitetura modernista, entre outras fortes expressões da arte brasileira.

Como situa Albino Rubim, tal "desenvolvimento da cultura brasileira [...] não tem qualquer correspondência com o que ocorre nas políticas culturais do Estado brasileiro. Elas, com exceção das intervenções praticadas pelo SPHAN, ${ }^{6}$ praticamente inexistem" (RUBIM, 2007, p. 18). Elas, as políticas culturais do governo federal, só ganhariam vulto na década seguinte, mais precisamente a partir de 1964, quando se instala no Brasil um novo ciclo de governos autoritários, então sob o comando dos militares, que só se encerra em 1984 com a eleição indireta de Tancredo Neves para a Presidência da República.

Se no governo Vargas se instaura o projeto de capitalismo moderno no Brasil, com o golpe militar em 1964 tem-se a reorganização econômica e política do país no sentido de aprofundar esse projeto. O Estado passa a operar dentro de uma lógica cada vez mais planejada. Num primeiro momento, percebe-se esse planejamento na política econômica. Depois, ele se estende a outras áreas de ação do governo, incluindo a cultural.

Como evidenciado, o interesse do movimento de 1930 com o nacionalismo é retomado pelo regime militar, porém com outras preocupações: a perspectiva de um mercado de bens simbólicos unificado e de uma nação integrada cultural e politicamente. Com efeito, o Estado brasileiro preocupava-se em criar uma rede de

5 Sobre as relações entre Estado e cultura no Brasil entre 1500 e 1930 ver Barbalho (2009). Para uma discussão mais aprofundada sobre a política cultural na era Vargas ver Barbalho (1998).

6 Serviço do Patrimônio Histórico e Artístico Nacional, criado por Vargas em 1937, a partir do anteprojeto elaborado pelo intelectual modernista Mário de Andrade. 
comunicação ligando todo o país, ao mesmo tempo em que a indústria cultural crescia num ritmo vertiginoso, sobretudo nos anos 1970. Assim, pretendia alcançar uma uniformidade nas informações que circulavam no território e padronizar a cultura e seu consumo diante das diversidades regionais.

Naquele momento, adequava-se à sociedade brasileira a caracterização de sociedade autoritária, trabalhada por Marilena Chauí $(1986 ; 2000)$. Ou seja, uma sociedade que produz uma ideologia da união nacional como forma de neutralizar as contradições. Com isso, a cultura popular, elemento central dessa ideologia, é apropriada pela classe dominante por meio de determinada visão do nacional-popular.

Ao trabalhar com o nacional-popular, Chauí (1986; 2000) aponta que os indicativos de cada uma das palavras remetem à representação de uma sociedade unificada. No entanto, a unidade não descarta a diversidade. O todo é diversificado (regiões/nação; grupos/povo), não se pode negar. Porém, no conceito o todo se torna a diversidade do que é, em si, uno e idêntico. O nacional reforça a identidade diante do que vem do exterior, enquanto o popular atua no reforço dessa dinâmica no interior do país. A junção das duas instâncias ocorre mediada pelo Estado. Compreende-se, então, por que a consolidação nacional se constitui, no regime militar, em políticas culturais do "estado para o Estado".

O conceito de integração nacional, determinante na ideologia de segurança nacional, retoma o pensamento de Durkheim para, como aponta Renato Ortiz (1985), funcionalizar a cultura como "cimento de solidariedade orgânica da nação". Com essa orientação, desenvolve-se uma política cultural que procura trabalhar as inevitáveis diferenças regionais no âmbito de ação maior dos "objetivos nacionais".

A preocupação do governo em controlar, como promotor, a produção cultural, principalmente a popular, e converter as manifestações regionais em nacionais permanecerá até os últimos momentos do regime. E, de certa maneira, será reforçada pelo surgimento dos novos movimentos sociais na abertura política a partir de 1979. É o que conclui Chauí (1986) ao analisar o plano trienal do Ministério da Educação e Cultura proposto em 1982, o último plano no setor apresentado pelo governo militar. 
Como podemos deduzir, o regime militar valoriza a cultura como elemento estratégico na sua tentativa de integrar a nação. Apropriando-se do conceito de nacional-popular, esvazia o discurso da esquerda e procura impor sua "interpretação" do país. Uma visão guiada por interesses militares e nacionalistas, reunidos na ideologia da segurança nacional, e econômicos, na busca da unificação do mercado de bens simbólicos, unindo diversas formas de utilização do nacional-popular.

O investimento dos governos militares na promoção da cultura se compreende quando percebemos as forças atuantes no campo cultural e a necessidade do regime de impor sua posição às outras. Nessa ótica, é preciso ter em mente a grande efusão intelectual, marcadamente de esquerda, pela qual passava o país no início dos anos 1960 e com a qual era preciso contrapor-se. O governo militar tentará neutralizar essa criação extremamente politizada, que continua mesmo após o golpe.

Todavia, o Estado militar não pretende restringir-se a uma ação repressora na cultura. Há o interesse em atuar na área, como forma de colocá-la sob sua orientação, justamente por evidenciar a dimensão e a força política da produção simbólica. Dessa maneira, é criado em 1966 o Conselho Federal de Cultura (CFC).

O CFC reúne intelectuais renomados, de perfil conservador, escolhidos entre instituições consagradas como o Instituto Histórico e Geográfico Brasileiro e a Academia Brasileira de Letras. Intelectuais bastante próximos ao poder e que participam ativamente, inclusive, da criação do Conselho.

Nesse sentido, o principal elemento unificador do CFC é a reverência ao passado, legitimando e explicando a ação presente e respaldando a posição desses intelectuais dentro do Conselho. O forte apelo ao passado, com um viés conservador, é fundamental na própria direção que o $\mathrm{CFC}$ dá à sua concepção de política cultural.

Com isso, o Estado alcança também uma continuidade com o passado, e o golpe apresenta-se não como uma ruptura, mas como a continuação com as raízes de um pensamento já estabelecido sobre a cultura nacional, principalmente nos anos do Estado Novo. Ou seja, é função desses intelectuais traçar um passado brasileiro propício ao regime militar e transformá-lo em "tradição". 
Paralelo ao papel do Estado e em ligação com este, ocorre o desenvolvimento da indústria cultural, que corresponde à necessidade de um crescente mercado consumidor de bens simbólicos. Aliás, essa é uma característica que difere a intervenção governamental na cultura pós-64 da ocorrida no Estado Novo, mesmo que o início da "sociedade de massas" no Brasil se dê nos anos 1930-40. A questão é que, a partir dos anos 1960, o volume de produtos simbólicos se multiplica. Ao mesmo tempo, passa por um processo de diferenciação, acompanhando a crescente segmentação do público.

Renato Ortiz (1989), ao comparar o mercado cultural nesses dois momentos, fala em duas ordens sociais distintas, tamanha era a diferença qualitativa e quantitativa entre os respectivos mercados. Como aponta Ortiz, durante o regime militar se consolidam as grandes empresas de comunicação de massa e da indústria cultural, empresas marcadas pelo capital estrangeiro, configurando-se numa área quase exclusiva das multinacionais. Temos, assim, os dois grandes investidores na cultura pós-64: o governo e as multinacionais.

Fixar essa dimensão econômica é necessário para compreendermos o outro lado da presença estatal na cultura. Presença que não tinha somente o sentido estritamente ideológico, mas também estava interessada no desenvolvimento econômico do país, do qual o mercado de bens simbólicos representava uma fatia considerável e em expansão.

A ideia de "organização pela cultura de massas" vai influenciar diretamente a política cultural do Estado, quando esta começa a valorizar a massificação e o consumo dos produtos culturais promovidos pelo governo. Nesse sentido, a industrialização da cultura e seu planejamento segundo valores econômicos transformam-na em espetáculo, e o "povo" em "público".

Otávio Ianni (1978), escrevendo no período, testemunha a dimensão da intervenção estatal na cultura e situa o Estado, entre 1964-1978, no centro da produção cultural brasileira. De acordo com o observado pelo autor, todas as condições de produção e de comunicação científicas ou culturais estavam sob controle ou influência das diversas instituições estatais. No entanto, a construção institucional do Estado militar na cultura ficou quase limitada às 
áreas de mercado restrito e dependentes de uma produção artesanal (música erudita, artes plásticas, teatro, etc.). Motivado por uma tendência "conservacionista" ou "patrimonialista", o Estado assume o papel de protetor do acervo histórico e artístico nacional e dos gêneros que só conseguem sobreviver com o apoio governamental.

Como contraponto da divisão do mercado de bens culturais, coube à iniciativa privada explorar as atividades de maior retorno econômico. Enfim, a presença do Estado restringiu-se basicamente às atividades eruditas ou da cultura popular, deixando para o capital privado a maior parcela dos gêneros e veículos mais rentáveis.

Na tentativa de exercer o controle sobre o campo cultural, o Estado precisa construir espaços onde possam ocorrer suas promoções, como se comprova com a criação do Conselho Federal de Cultura e do Instituto Nacional do Cinema, ambos em 1966. Contudo, essa estruturação ganha nova dinâmica no governo Geisel (1974-1978), durante a gestão de Ney Braga no Ministério de Educação e Cultura (MEC). Esse período representa o ápice da busca em adequar uma ação cultural às pretensões políticas do regime.

É quando a área da cultura passa por amplo desenvolvimento com a implantação do Conselho Nacional de Direito Autoral e do Conselho Nacional de Cinema, o lançamento da Campanha de Defesa do Folclore Brasileiro, a reformulação da Empresa Brasileira de Filmes, a criação da Fundação Nacional de Artes, a expansão do Serviço Nacional do Teatro, entre outros acontecimentos. Em 1975, é lançada também a Política Nacional de Cultura (PNC), primeiro plano de ação governamental no país que trata de princípios norteadores de uma política cultural.

Embora a PNC não tenha alcançado plenamente seus objetivos, ela se torna importante porque representa uma iniciativa, e não uma mera reação por parte do Estado a pedidos ou projetos particulares dos artistas e intelectuais. Tomar a iniciativa nunca foi a prática predominante das ações governamentais no campo da cultura, campo sempre desprestigiado em relação a outras áreas de investimento social.

Dessa forma, podemos compreender a PNC como uma tentativa de ampliar esse investimento na trilha aberta pelo "milagre econômico". Para Miceli (1984), a PNC significou a incorporação 
da cultura nas metas da política de desenvolvimento social do governo. Primeiro momento da nossa história em que o governo formaliza diretrizes de atuação no setor, prevendo colaborações de outros setores do poder federal, dos poderes estaduais e municipais, além do setor privado.

À ampliação da política de desenvolvimento, além da importância estratégica conferida à política cultural, somam-se a influência e a capacidade de pressão por parte dos grupos a que pertencem o ministro Ney Braga e sua equipe no MEC para explicar o investimento cultural pós-1975. Nesse sentido, é fundamental o papel dos dirigentes na ampliação da ação cultural, ou dos parentes de figuras poderosas dentro do governo que usam das suas influências para apoiar artistas e intelectuais. Isso demonstra que mesmo com um plano de cultura, sua atuação é muito aleatória e baseada em critérios personalistas, mantendo relações de clientelismo e assistencialismo.

Ortiz (1989) segue o mesmo raciocínio e sugere que a PNC só pôde surgir dez anos depois do golpe militar como resquício do "milagre econômico", através do II Plano Nacional de Desenvolvimento (1974-1976). Com o plano, Geisel pretendia alcançar certa distribuição de renda e a cultura passa a ser vista como uma forma indireta para viabilizar essa distribuição. Desse modo, o "milagre", de certa maneira, é responsável pela intenção dos administradores governamentais de ampliar a participação do Estado na cultura. Assim, com a crise, evidente a partir de meados da década de 1970, as ideias e as intenções que estavam na PNC ou não serão realizadas ou sofrerão reformulações para se adaptarem à nova realidade econômica, longe da euforia.

\section{POLÍTICA CULTURAL NA COSTA RICA (1950-1980): APOGEU E CRISE DA SOCIAL-DEMOCRACIA}

A década de 1950 na Costa Rica começa sob uma nova égide política, após a guerra civil em 1948 que tirou do poder as oligarquias liberais que governaram o país desde a independência no século XIX. No intuito de civilizar a população costa-riquense e modernizar a capital San José, as elites liberais implantaram diversas ações educativas e culturais, como, por exemplo, uma ampla 
campanha de alfabetização, ${ }^{7}$ de modo que o país tem hoje um dos menores índices de analfabetismo da América Latina. Além disso, deram início à construção institucional na área cultural com a criação do Teatro Nacional e da Escuela Nacional de Bellas Artes (1897), do Templo de la Música (1920) e da Universidad de Costa Rica (1941), além do incentivo ao crescimento e consumo das indústrias culturais e das mídias massivas (imprensa, rádio, cinema, música popular).

Todas estas transformações ao longo do século XIX e primeira metade do século seguinte propiciaram, na avaliação de Patrícia Vargas, "a configuração de novas identidades e práticas culturais" (VARGAS, 2005, p. 7), interferindo tanto na cultura política, quanto na política cultural vigentes no país - o que se fará sentir na construção da nova configuração político-social pós-48 organizada em torno do ideário social-democrata.

Apesar da presença dos governos liberais na cultura, alguns dos principais intelectuais costa-riquenses da segunda metade do século compartilham um sentimento de vazio cultural naqueles anos de liberalismo. Isaac Felipe Azofeifa, por exemplo, recorda que quando retornou do Chile onde foi estudar nos anos 1940 estranhou a escassez de livrarias, a ausência de editoras e de galerias de arte, e que os estudos de filosofia tivessem parado em São Tomás! Na sua avaliação, a vida intelectual da Costa Rica era "deprimente". Isto porque, até então, a classe dirigente do país "era a classe campesina rica absolutamente ignorante, ignorante do que ocorria no mundo da cultura e inclusive da política" (AZOFEIFA apud MOLINA, 2006, p. 26). Sensação parecida teve Rafael García, pouco depois, em 1956, quando voltou ao país. O que encontrou foi um meio cultural raquítico, sumamente pobre onde não se passava nada: não havia exposições, as pessoas não tinham lugares para reunião e ninguém dava importância à arte; eu diria que esta era uma sociedade "adormecida", porque se sentia não apenas um grande vazio cultural, mas também social (GARCÍA apud MOLINA, 2006, p.147).

7 Em 1927, 86,7\% da população urbana e 61,3\% da rural estavam alfabetizadas. Em 1950, os dados eram bem melhores: $91,9 \%$ da população urbana e $71,5 \%$ no setor rural eram alfabetizados. A esse respeito ver Vargas (2005). 
Na periodização feita por Rafael Molina (2007), o projeto político e ideológico dos liberais tem dois momentos. O primeiro, da independência até fins do século XIX, marcado por fortes resquícios coloniais, e o segundo, na primeira metade do século XX, considerado fundamental para a construção da moderna identidade dos costa-riquenses. Ora, é este projeto que entra em crise no final dos anos 1940 e cede espaço para a reorientação identitária proposta pelos grupos social-democratas. Por fim, situa Molina, nos anos 1980, o projeto neoliberal vitorioso impõe um novo modelo de identidade nacional à Costa Rica - voltaremos a abordar este ponto no final do artigo.

O núcleo elaborador das concepções político-culturais dos social-democratas se reuniu em torno do Centro para el Estudio de los Problemas Nacionales, fundado em 1940. Em contraposição ao ideário liberal que entendia a cultura como um bem individual, os chamados "centristas" defendiam sua função social e diretiva, no sentido de indicar aos cidadãos atividades e objetivos coletivos. Os bens culturais a serem difundidos não seriam nem os das elites, porque limitados, nem os do povo, porque considerado inculto, mas aqueles produzidos pelos intelectuais que possuíam os únicos instrumentos para compreender os "ticos"8 e o "autenticamente nacional".

Segundo se informa no primeiro documento lançado pelo Centro, intitulado Quiénes somos, integrantes da instituição se agruparam em torno de um propósito cultural, qual seja, o de que os "homens de estudo" devem assumir a "obrigação moral" da sua função de direção, que seria elevar o cidadão à consciência de suas responsabilidades, à compreensão e gozo da sua liberdade e à cooperação no aperfeiçoamento das formas sociais de vida. Assim, a cultura é entendida como "serviço social, força educadora". O documento defende explicitamente a "necessária unidade entre cultura e política", campos até então considerados radicalmente distintos.

O Centro para el Estudio de los Problemas Nacionales se constitui a partir de setores da classe média que assumem posições estratégicas com a subida ao poder dos social-democratas e a construção

8 Nome com o qual são conhecidos os costa-riquenhos. 
do Estado Social. ${ }^{9}$ Como situa Fernando Volio, um dos principais personagens da política cultural dos governos social-democratas, a cultura estava "no campo da participação do Estado na produção do bem-estar geral" e era uma questão central para a nova república que se formava (VOLIO apud MOLINA, 2006, p. 78).

O mecenato à cultura, formato da política naquele início de governo, se institucionalizou ao se transformar em artigo constitucional com a Assembleia Nacional Constituinte de 1949. Entre as atribuições da Assembleia Legislativa estava: "Promover o progresso da ciência e das artes e assegurar por tempo limitado aos autores e inventores a propriedade de suas respectivas obras e invenções". Em outro inciso da Constituição, o Estado obriga-se a: "Criar estabelecimentos para o ensino e o progresso das ciências e das artes, garantindo orçamento para seu sustento e procurar expressamente a generalização do ensino primário".

A partir daquele momento, se criam novas instituições e ações voltadas especificamente para a cultura como a Editorial Costa Rica e a Asociación de Autores, a Ley de Premios Nacionales, a Dirección General de Artes y Letras (DGAL), um departamento com bastante autonomia no interior do Ministério de Educación. A DGAL cria diversos espaços como galeria de arte, escola de dança e promove eventos culturais que buscam, assim, incentivar os produtores especializados de cultura e responder à demanda de consumo de bens simbólicos mais refinados por parte da crescente classe média, em especial daquela formada nos quadros da Universidad de Costa Rica.

Na avaliação de Guido Sáenz, outro importante agente da política cultural costa-riquense do período social-democrata, e ex-ministro da Cultura, a DGAL foi "a primeira manifestação de um interesse já propriamente do Estado" em relação ao patrocínio da cultura (SÁENZ apud MOLINA, 2006, p. 108). Ou das "minorias", que é como chama os intelectuais e os artistas do país, minorias

9 Entre 1948 e 1980, período de hegemonia do projeto social-democrata, foram criadas em torno de 100 novas instituições estatais, a ponto de, no início da década de 1980 quase 20\% dos empregos serem públicos. Segundo observa Iván Jiménez, o país pós-48 "se organizou, de fato, em torno de um estendido setor público, garantidor dos direitos, empregos, poupanças, serviços sociais, propriedades e, sem dúvida, o futuro de seus habitantes" (JIMÉNEZ, 2007, p. 32). 
silenciosas, sem direito à voz, nem voto, pois sempre desprezadas pelos políticos liberais. A DGAL foi a primeira tentativa séria de se estabelecer canais de comunicação entre o Estado e os criadores culturais. Mesmo com poucos recursos, a instituição apoiou os artistas por meios diversos, de modo a colocá-los em contato com a opinião pública.

Molina aponta as três linhas da política cultural social-democrata: mecenato, difusão e promoção. O mecenato é voltado para os artistas e intelectuais como forma de proporcionar-lhes condições de produção e assume vários formatos, com destaque para os programas de bolsas da DGAL e as leis de proteção à criação e à circulação artísticas. A política de difusão objetiva levar a cultura feita pelos especialistas à população de todas as regiões da Costa Rica. Na avaliação de Molina, a expansão cultural é a principal expressão do projeto social-democrata. Por fim, há as ações de promoção que só ganham vulto tardiamente, no final dos anos 1970, e se destinam a estimular a criação entre aqueles que não são produtores culturais especializados. Seus espaços institucionais são as Casas de Cultura e o Programa de Formação de Promotores Culturais.

Aliás, na década de 1970 ocorrem o apogeu e a crise do projeto social-democrata e, portanto, da sua política cultural. Nestes anos foram criados a Compañía Nacional e o Taller Nacional de Teatro, se reorganizam a Orquestra Sinfónica Nacional, o Centro Costarricense de Producción Cinematográfica, o Museo de Arte Costarricense, e se retomam os Salones de Artes Plásticas, entre outras ações. O ponto máximo da institucionalização da política cultural se verifica com a criação em 1970 do Ministério de Cultura, Juventud y Deportes (MCJD). ${ }^{10}$ Como informa Iván Jiménez (2007), paralelo a esta intervenção estatal na cultura, observa-se na segunda metade do século XX o incremento da produção e do consumo de bens gerados pelas indústrias culturais, com destaque para a inauguração da televisão no país na década de 1960.

10 Importa destacar que nos anos 1960 e 1970, vários países da América Latina, como o Brasil, imergiram em regimes autoritários, enquanto a Costa Rica, desde a guerra civil de 1948, que inclusive extinguiu o exército, vive em regime democrático. Isso motivou a migração de intelectuais e artistas para o país, em especial vindos do Chile, o que impulsionou ainda mais a produção cultural costa-riquense. A esse respeito ver Pérez (2005). 
No entanto, em todo este período não houve propriamente a formulação ou o planejamento das políticas culturais, a começar pelo Centro para el Estudio de los Problemas Nacionales. Segundo um dos seus integrantes, Alberto Cañas, não se desenvolveu ali uma política cultural, tanto que, uma vez no poder, os intelectuais ligados à social-democracia não possuíam um projeto de cultura. Essa situação, em curso no início dos anos 1950, perdura pelo restante do século. Conforme reconhece Cañas, a partir dos anos 1960 começa a se desenvolver uma política voltada para a cultura, mas, na sua avaliação, não aconteceu uma formulação prévia do que seria feito. As ações respondiam às necessidades e depois tudo que foi se constituindo se transformou em um documento e se descobriu haver uma política! E uma política basicamente de mecenato, onde "o Estado é convertido em mecenas dos artistas e dos literatos [...] sem se criar problemas sobre a finalidade" (CAÑAS apud MOLINA, 2006, p. 51).

Esse foi o caso, inclusive, da instituição do Ministério de Cultura, Juventud y Deportes. Depois da criação da Editorial Costa Rica, da Asociación de Autores e dos prêmios nacionais, começou um movimento reivindicando a formação de um ministério exclusivo para a cultura. Uma vez criado o ministério (que não se restringiu à cultura, como vimos), seus programas foram elaborados como se pertencessem ao Ministério da Fazenda. Na comparação irônica de Cañas: "O que há para fazer? Com que recurso? E assim por diante. Sem quebrar a cabeça, nem matar-se pensando dentro de qual marco" (CAÑAS apud MOLINA, 2006, p. 52).

O resultado desse desencontro de ideias sobre a especificidade da cultura e de suas políticas está na formação de um ministério que envolve a cultura com o esporte e a juventude. Na avaliação de Fernando Volio houve um erro na concepção inicial do MCJD ao reunir em um mesmo órgão executivo três campos tão vastos. Some-se a isso a dificuldade do governo em votar na Assembleia Legislativa a lei da sua criação: havia muita oposição à ideia e, ao mesmo tempo, pouco empenho do governo em criá-lo. Assim, "o Ministério da Cultura nasceu mal. Foi uma excelente ideia, era necessário criá-lo, mas nasceu mal com esta tríplice função, com 
pouco orçamento, nasceu inclusive desprestigiado porque não saía, não saía e não saía" (VOLIO apud MOLINA, 2006, p. 91).

Apesar de todas essas insuficiências, na avaliação de Guido Sáenz, ao final do período social-democrata, a situação do campo cultural costa-riquense tinha se transformado substancialmente:

Desde então você vê gente que tem interesse por teatro, por música, pelos concertos, por estudar música, que faz da música sua vida, os pintores que fazem da pintura seu modus vivendi, que mantêm suas famílias, já são profissionais, já são cidadãos com voz e voto, que têm profissionalmente um valor e o respeito dos concidadãos [...].

Houve uma sensibilização para a cultura, as pessoas se davam conta agora da existência dessas coisas, voltavam a ver, o que não faziam antes pois passavam com a indiferença mais absoluta, inclusive com desprezo, com desdém, os artistas eram vistos como vagabundos bêbados, gente de má vida; houve uma valorização do ser humano-artista-criador (SÁENS apud MOLINA, 2006, p. 123).

Em outras palavras, para retomar uma qualificação do próprio Sáenz ora referida, os agentes culturais deixaram de ser uma minoria!

\section{POLÍTICA CULTURAL NO BRASIL E NA COSTA RICA: PARALELAS QUE SE CONECTAM?}

Como podemos observar, Brasil e Costa Rica viveram na segunda metade do século XX momentos extremamente ricos em suas políticas culturais. Ficam bem evidentes, também, ao longo do texto, as profundas diferenças a separar as duas experiências. Seriam como duas paralelas que, no máximo, se cruzariam no infinito!

No entanto, mais do que as diferenças que separam os dois países nos campos cultural e político, interessa perceber o que neles se assemelha. Interessa ver se entre essas paralelas é possível estabelecer algumas conexões.

A primeira dessas conexões seria o fato de ambas as políticas atingirem seu auge na década de 1970. Podemos levantar como hipótese dessa coincidência temporal o fato de serem os últimos anos do chamado "período de ouro do capitalismo" e da sua política desenvolvimentista aplicada pelos organismos nacionais e internacionais nos países do então Terceiro Mundo. A perspectiva de um desenvolvimento ampliado teria motivado o Estado a 
investir em áreas historicamente marginalizadas pelas políticas públicas em ambos os países, como era o caso da cultura.

Outro elemento presente nas políticas culturais do Brasil e da Costa Rica era a preocupação identitária. Seja por uma questão de segurança e integração nacional, no primeiro caso, seja para demarcar um novo projeto político-social, o da social-democracia, no segundo. Independente das intenções, importa perceber que naqueles anos havia forte componente nacionalista traduzido em diversas linhas de pensamento e de políticas, inclusive entre consideráveis parcelas dos desenvolvimentistas.

Por fim, podemos arriscar outras conexões entre as duas políticas culturais: o neoliberalismo e a globalização, os quais chegam com força crescente a partir dos anos 1980 e que reconfiguram os valores até então vigentes. A questão seria perceber as diferentes reações político-culturais a este estado de coisas no Brasil e na Costa Rica, mas também as semelhanças.

Como situa Canclini (2002), o que significa falar em uma suposta identidade continental em meio ao forte processo de globalização, de crise do Estado-nação, de redefinição do popular, das migrações em massa, das alterações de fronteiras entre o periférico e o central?

Com as migrações de latino-americanos, em especial para a Europa e os Estados Unidos, e com o fluxo mundializado das produções simbólicas originárias daquela parte do continente, sentir-se da América Latina não implica mais estar fixado em alguma parte do território entre o México e a Argentina. Ademais, habitar algum dos países latino-americanos já não garante mais uma "identidade nacional" ou "regional" estável, integradora do "ser". Esta sensação de desterritorialização não resulta apenas da mundializacão da cultura (WARNIER, 1999) e do consumo intenso dos seus produtos, que Ortiz (1998) denomina de cultura internacional-popular, a qual vem se sobrepor à nacional-popular.

À crise dos parâmetros culturais endógenos aos quais recorriam os ideólogos da nacionalidade há de somar outro dado, de ordem político-cultural e social, isto é, o questionamento feito por dentro da nação por aqueles setores marginalizados pela tradição inventada que sustenta o discurso identitário: a herança europeia do homem branco cristão.

Contra a história oficial insurge o pensamento liminar com suas histórias locais (MIGNOLO, 2003). Pensamento liminar 
formado pelos "saberes sujeitados", aqueles que, como situa Foucault (1999), eram desqualificados por não serem conceituais, elaborados, e qualificados como ingênuos e inferiores.

São esses saberes, construídos na história das suas lutas, que trazem os chamados "novos movimentos sociais" e que se somam à tradição de resistência dos movimentos operários, campesinos e indígenas latino-americanos: os movimentos feministas, dos jovens, dos afrodescendentes, dos ecologistas, dos homossexuais, enfim, das diversas minorias e seus devires (BARBALHO; PAIVA, 2005). Cada um deles possui sua própria comunidade imaginada (ANDERSON, 1993) e a negocia com aquela mais ampla, que procura impor-se como totalidade integradora, como hegemonia, que é a das elites da nação.

O certo é que antes também não era fácil colocar as diversidades e as diferenças inter e intranacionais da América Latina em uma única definição, de uma mesma comunidade latino-americana. Nem mesmo com toda a produção simbólica a circular no continente por meio das suas indústrias culturais, desde os romances do boom do realismo mágico, passando pelas telenovelas brasileiras e mexicanas, até os variados ritmos musicais que marcam para nós e para os outros, em especial europeus e norte-americanos, os nossos tipos.

Assim, hoje como antes, apesar de certa comunidade linguística hegemonizada pelo castelhano e pelo português e uma história bastante convergente, é difícil agrupar dentro da mesma identidade cultural países com poderosa capacidade de criação, circulação e consumo culturais, tais como Brasil, Colômbia, México e Argentina, com países onde o mercado de bens simbólicos é restrito, como ocorre com os da América Central (BARBALHO, 2011). Por essas e outras razões, afirma Canclini, está desautorizado "qualquer relato não suficientemente polifônico, com fortíssimos e pianíssimos, para transmitir a heterogeneidade da América Latina, suas variadas escalas de desenvolvimento" (CANCLINI, 2002, p. 25). ${ }^{11}$

11 No original: "[...] culquier relato no suficientemente polifônico, con fortíssimos y pianíssimos, como para transmitir la heterogeneidad de America Latina, sus variadas escalas de desarrollo" (Tradução minha, destaques no original). 


\section{REFERÊNCIAS}

ANDERSON, Benedict. Comunidades imaginadas: reflexiones sobre el origen y la difusión del nacionalismo. Cidade do México: Fondo de Cultura Econômica, 1993.

BARBALHO, Alexandre. Políticas e indústrias culturais na América Latina. In: XV CONGRESSO BRASILEIRO DE SOCIOLOGIA, 15., 2011, Curitiba. Anais... Curitiba: UFPR, 2011. v. 1. p. 1-15.

. Políticas culturais no Brasil: primórdios (1500-1930). In: ENECULT, 5., 2009, Salvador. Anais... Salvador: UFBA, 2009. Políticas culturais no Brasil: identidade e diversidade sem diferença. In: BARBALHO, Alexandre; RUBIM, Albino (Orgs.). Políticas culturais no Brasil. Salvador: UFBA, 2007. Relações entre Estado e cultura no Brasil. Ijuí: Unijuí, 1998.

BARBALHO, Alexandre; PAIVA, Raquel (Orgs.). Comunicação e cultura das minorias. São Paulo: Paulus, 2005.

BAUDRILLARD, Jean. Para uma crítica da economia política do signo. Rio de Janeiro: Elfos, 1995.

CANCLINI, Nestor Garcia. Latinoamericanos buscando lugar en este siglo. Buenos Aires: Paidós, 2002.

Consumidores e cidadãos: conflitos multiculturais da globalização. Rio de Janeiro: UFRJ, 1997. CHAUÍ, Marilena. Brasil: mito fundador e sociedade autoritária. São Paulo: Perseu Abramo, 2000.

Conformismo e resistência: aspectos da cultura popular no Brasil. São Paulo: Brasiliense, 1986.

DEBORD, Guy. A sociedade do espetáculo. Rio de Janeiro: Contraponto, 1997.

FOUCAULT, Michel. Em defesa da sociedade. São Paulo: Martins Fontes, 1999. 
IANNI, Otávio. O Estado e a organização da cultura. Revista Encontros com a Civilização Brasileira, Rio de Janeiro, v. 1, p. 216-241, 1978.

JIMENEZ, IVan. Identidad nacional y cambio cultural en Costa Rica durante la segunda mitad del siglo XX. San José: Universidad de Costa Rica, 2007.

MICELI, Sergio. O processo de "construção institucional" na área cultural federal (anos 70). In: Estado e cultura no Brasil. São Paulo: Difel, 1984. p. 53-84.

MIGNOLO, Walter. Histórias locais / projetos globais: colonialidade, saberes subalternos e pensamento liminar. Belo Horizonte: UFMG, 2003.

MOLINA, Rafael. Tendencias de la dinámica cultural en Costa Rica en el siglo XX. San José: Universidad de Costa Rica, 2007.

Cultura y política en Costa Rica: entrevistas a protagonistas de la política cultural en la según mitad del siglo XX. San José: EUNED, 2006.

ORTIZ, Renato. Mundialização e cultura. São Paulo: Brasiliense, 1998.

A moderna tradição brasileira: cultura brasileira e indústria cultural. São Paulo: Brasiliense, 1989.

Cultura brasileira e identidade nacional. São Paulo: Brasiliense, 1985.

PEREZ, Guilermo. Cultura artística y popular en Costa Rica: 1950-2000. Entre la utopía y el desencanto. San José: Universidad de Costa Rica, 2005.

RUBIM, Albino. Políticas culturais no Brasil: tristes tradições, enormes desafios. In: BARBALHO, Alexandre; RUBIM, Albino (Orgs.). Políticas culturais no Brasil. Salvador: UFBA, 2007. VARGAS, Patrícia. Cultura y sociedad en Costa Rica. San José: Universidad de Costa Rica, 2005.

WARNIER, Jean-Pierre. La mondialisation de la cultura. Paris: La Découverte, 1999. 